\title{
A forças conservadoras da vida como possibilidade de enfrentamento à dialética opressão/insurgência em face a cultura de paz
}

\section{The Conservative Forces of Life as a Possibility of Facing the Dialectics Oppression/Insurgence Facing the Peace Culture}

\author{
Carla Jeane Helfemsteller Coelho ${ }^{1}$ \\ ORCID: https://orcid.org/0000-0003-1240-9981 \\ UNIT (Brasil) \\ Liziane Paixão Silva Oliveira ${ }^{2}$ \\ ORCID: https://orcid.org/0000-0002-6266-6073 \\ UniCEUB - UNIT (Brasil)
}

Recibido: 30-04-2021

Aceptado: 30-08-2021

\footnotetext{
${ }^{1}$ (ccfilos2@yahoo.com.br) Filosofa, Doutora em Educação. Professora nos Programas de PósGraduação em Educação e Direitos Humanos da UNIT. Publicações:

Rubio, D. S. (Org.); Oliveira, L. P. S. (Org.); Coelho, Carla Jeane Helfemsteller (Org.): Teorias Críticas e Direitos Humanos: contra o sofrimento e a injustiçasocial. 1. ed. Curitiba: CRV, 2016. v. 1. $384 \mathrm{p}$.

Coelho, Carla Jeane Helfemsteller; Linhares, H. S. ; Reboucas, G. M.: "Arte e educação em direitos humanos: sensibilização e sensibilidades por justiça social". Interfaces Cientificas - Educação, v. 8, pp. 231-243, 2020.

2 (lizianepaixao@gmail.com). Doutora em Direito Internacional pela Université d' Aix-Marseille III, Mestre em Direito pela UNB, Professora do Mestrado e Doutorado em Direito do CEUB e da Universidade Tiradentes., Líder do Grupo de Pesquisa vinculado ao CNPq Direito, Políticas Públicas e Inovação. Advogada. Consultora. Publicações:

Oliveira, Liziane Paixão Silva; Barros Platiau, Ana Flávia; Barros, Jorge Gomes do Cravo: "Mitigating the Principle of Sovereignty over Biological Resources?". Nomos (Fortaleza), v. 38, pp. 244-256, 2018.

Oliveira, Liziane Paixão Silva; Jaborandy, C. C. M.: "Uncostitutional state of affairs and the protection of minimum rights in Brazil". Revista Jurídica- Unicuritiba, v. 3, p. 166-184, 2018.
} 


\title{
Resumo
}

A Paz é possível sempre intercalada com a ausência dela. Sistemas necropolíticos obstaculizam a paz. A dissociação do sujeito impede a ação da força seletiva, bloqueia o potencial humano, tornando-o acrítico. A integração da multidimensionalidade humana proporciona a expressão do potencial e ação da força seletiva e leva o sujeito à reflexão crítica e à sensibilização que o habilita a criar estratégias contra hegemônicas. Conhecimentos e saberes carregam uma carga axiológica; valores são aprendidos e ensinados. A saída está na educação. A esperança e a indignação pela ausência dela, constituise desafio a todo processo educativo. As propostas de Espinosa e de Rolando Toro Araneda, em diálogo com Ferdinand Röhr e Paulo Freire, constituem-se filosofias que apontam as condições de possibilidade com as quais engendramse estratégias cujo desafio seja educar para a paz. Nesse contexto, o artigo se propõe a refletir sobre propostas epistêmico-éticas que contribuem para a paz.

Palavras-chave: Educação, paz, subjetividade, filosofia.

\begin{abstract}
Peace is possible even though it is always interspersed with its absence. Necropolitical systems hinder peace. The dissociation of the subject, preventing the action of selective force in the face of obstruction of human potential, makes it a-critical, unable to find overcoming strategies. It is the integration of human multidimensionality providing the expression of the potential and action of selective force that can lead the subject to critical reflection and awareness that enables them to create strategies against hegemonic. Knowledge and knowledge carry an axiological burden; values are learned and taught. The way out is in education. Hope and indignation for her absence is a challenge to the whole educational process. The proposals of Espinosa and Rolando Toro Araneda, in dialogue with Ferdinand Röhr and Paulo Freire, constitute philosophies that point out the conditions of possibility with which, not accepting any educational process, strategies are created whose challenge is to educate for peace. In this context, the article proposes to reflect on epistemic-ethical proposals that contribute to peace.
\end{abstract}

Keywords: Education, peace, subjectivity, philosophy. 


\section{Primeiras palavras - Introdução}

Quais as condições para a paz?

A reflexão sobre a paz aqui apresentada toma dois caminhos os quais consideramos indispensáveis e indissociáveis: o caminho que perscruta a paz interior, do ponto de vista individual; e o caminho que perscruta a paz considerando a coletividade, como descreve Cabezudo (2010: 244), abarcando diferentes dimensões tais como equidade e justiça, dignidade e solidariedade, respeito aos direitos dos povos e diversidade cultural.

Entendemos que a reflexão sobre a paz precisa considerar a relação entre paz individual e paz em termos de coletividade como indissociáveis, tendo em vista que as relações sociais são constituídas por relações intersubjetivas. Daí a importância de se olhar para o sujeito para pensar o social e a formação cultural.

Reconhecemos que o significado do que seja paz, do ponto de vista individual, encerra um caráter singular que torna a percepção e sentido do que, para cada pessoa representaria seu estado de paz, algo pessoal e exclusivo. Todavia podemos inferir que alguns fatores são condições de possibilidade para a paz individual, esclarecendo que esta não é linear e contínua e que do ponto de vista individual a sensação de paz será sempre intercalada com a sensação da ausência dela. Como nos ensina a sabedoria do I Ching (da tradição chinesa) quando nos lembra que paz não é ausência de conflito, cujo oposto é a estagnação, mas sim a presença de movimento que indica o triunfo do processo (Wilhelm 1982).

Dor (física e psicológica), doença, carência das necessidades básicas para fruição da dignidade são fatores que impedem a paz individualmente. Para algumas pessoas pode ser incluída ainda a solidão, o desamparo, visto que se pode identificar ausência de paz interior em pessoas que tem suas necessidades materiais supridas.

Igualmente quando falamos de necessidades individuais entramos novamente em um campo singular, dado o amplo aspecto de subjetividade que encerra o significado de necessidade individual. Para uma pessoa que não tem suas necessidades básicas satisfeitas pode ser estranho constatar que outra pessoa com suas necessidades materiais satisfeitas, também vive a ausência de paz.

Optamos, pois, pelo viés da subjetividade para refletir sobre a paz, trilhando o caminho do individual para o coletivo e considerando a importância do primeiro para o segundo. Isto porque a coletividade (ou se preferir, a sociedade) constitui-se dos componentes epistêmico-axiológicos das subjetividades daqueles que a compõe, e nesta coletividade se produz a cultura, a qual dialeticamente interfere na construção destas subjetividades. 
Apresentamos, portanto, multidisciplinarmente - como entendemos ser necessário à esta empreitada - alguns fatores considerados fundamentais na construção das subjetividades, tomados aqui enquanto condições subjetivas necessária à paz individual e consequentemente à paz coletiva.

A saber: 1) a capacidade do ser humano acessar sua força seletiva que escolhe o que favorece a conservação da vida, distinguindo-a das ameaças. Tal força é denominada pelo filósofo Espinosa como conatus. Esta capacidade torna possível e é possibilitada mediante 2) a ativação dos canais que expressam o potencial genético presente no ser humano, de acordo com o epistemólogo latino-americano Rolando Toro Araneda. Por fim, 3) a necessidade de integração do ponto de vista da multidimensionalidade do ser humano, como propõe Röhr, uma vez que tal integração é indispensável às duas primeiras capacidades.

Sem pretender esgotar tema de tamanha complexidade nesse artigo, nos debruçaremos nas lições das filosofias de Espinosa e da epistemologia de Rolando Toro Araneda, em diálogo com outros pensadores tais como Ferdinand Röhr e Paulo Freire, com a pretensão de, perscrutando a construção da subjetividade à luz de suas propostas, apontar filosofias ou propostas epistêmico-éticas que contribuem para pensarmos as condições de possibilidade para a paz.

\section{O desafio educativo à construção do sujeito}

Paz não será um conceito definido univocamente. Se invocarmos o educador Paulo Freire através de sua obra Pedagogia do Oprimido de 1981, podemos capturar uma associação entre humanização, paz e educação quando ele coloca a humanização como desafio educativo que resulta em uma incessante conquista no desenrolar da ambiguidade da vida, em sua permanente tensão humanização-desumanização. E da humanização depende a paz, enquanto fenômeno eminentemente humano.

Esta humanização, para Freire, pode também ser caracterizada pelo ser mais como bem reflete Streck e Viola (2010: 140). Estes definem a paz à luz das considerações freireanas não como ausência de conflitos e tensões, mas como condição para o processo de ser mais. Processo este que ocorre por dentro de todas as modalidades educativas: formal, não formal e informal. Este processo de ser mais, do ponto de vista freireano, pode ser explicado pela proposição do analista junguiano James Hillman (2001), quando afirma que o indivíduo consegue ser mais quando é o que vem a ser, ou, quando encontra as condições para realizar seu proposito existencial. Proposito este não definido a priori, mas reconhecido pelo sujeito mediante as interações permanentes entre os fatores endógenos e exógenos ao longo da existência. Diz Hillman (2001: 14): “existe uma razão por que minha singular pessoa está aqui e que há coisas que preciso 
cuidar além da rotina diária, e isso deve dar uma razão de ser a esta rotina".

Estas definições apontam para a necessidade de atenção ao desenvolvimento da individualidade como condição para a construção de uma subjetividade que corresponda à humanização, destaca que isto ocorre mediante processos educativos salientando, portanto, a importância de uma educação humanizadora, esclarecendo que deste desenvolvimento depende a paz.

Nesse contexto, o grande desafio educativo é a criação de uma cultura de paz a qual precisa incluir valores que propiciem a paz. A capacidade da luta pela esperança e da denúncia de qualquer ameaça à ela, é critério indispensável para pensarmos processos educativos humanizadores, tanto em relação ao sujeito, já que esta capacidade é inerente à ele, como ensina Freire, como tendo estas capacidades enquanto fim teleológico de todo processo educativo. A esperança - e a indignação pela morte da esperança - constitui-se desafio a todo processo educativo, mediante a assunção de compromissos com amanhãs onde, não aceitando qualquer processo educativo, engendram-se forças e estratégias para contribuir com processos cujo desafio seja educar para a paz; o que seria para o filósofo Adorno (1995) educar para não repetir Auschwitz.

Em seu livro Pedagogia da Esperança (1992) Paulo Freire escreveu que a tarefa da educação não consistia em educar a esperança, uma vez que esta seria condição ontológica de todo ser humano. Cabia à educação cuidar para que esta esperança não perdesse o rumo e no fim acabasse em desespero. O mesmo pode ser dito em relação à raiva ou à indignação que ele vê como emoções nas quais se assenta a capacidade de agir pela mudança. Uma "ética universal do ser humano" será constituída na relação dialética entre denúncias das ações “necrofílicas” e a afirmação das forças “biofílicas”. (Streck y Viola 2010: 143)

Diante deste desafio lançamos perguntas que impulsionam a reflexão ora apresentada, tais como: o que possibilita então a emergência da esperança e da "justa raiva" face à sua aniquilação, aparentemente recalcadas em uma nebulosa sombra niilista que parece recrudescer o humano?

Tenho o direito de ter raiva, de manifestá-la, de tê-la como motivação para minha briga tal qual tenho o direito de amar, de expressar meu amor ao mundo, de tê-lo como motivação de minha briga porque, histórico, vivo a História como tempo de possibilidade e não de determinação. Se a realidade fosse assim porque estivesse dito que assim teria de ser não haveria sequer porque ter raiva. Meu direito à raiva pressupõe que, na experiencia histórica da qual participo, o amanhã não é algo pré-dado, mas um desafio, um problema. A minha raiva, minha justa ira, se funda na minha revolta em face a negação do direito de "ser mais" inscrito na natureza dos seres humanos. (Freire 1996: 84)

Se estas condições são ontológicas a todo ser humano, o que ativa as forças biofílicas? Entendemos que as forças biofílicas freireanas, que podem ser explicadas também a partir da ideia de conatus de Espinosa, são fortalecidas 
quando a pessoa tem as condições de estar integrada. A dissociação enfraquece estas forças. Por esta razão vamos ver o que entendemos por integração do humano, já que estamos defendendo ser esta uma condição para a assunção das forças biofílicas - ou conatus, as quais podem contribuir para a expressão dos potenciais humanos que dialeticamente conduzem estas forças, e que são condições para a paz do ponto de vista da individualidade - que refletirá na coletividade.

\section{A multidimensionalidade do ser humano como condição à integração dele}

Ao propor a multidimensionalidade do ser humano, Ferdinand Röhr (2010: 217) deixa claro que tem consciência do risco de reducionismos nas tentativas de explicar a realidade, dada a sua complexidade. Tal risco, todavia, não impede que se busque apresentar uma proposta e explica-la, apenas procura deixar clara a consciência que se tem sobre os limites desta empreitada.

Tendo feito esta advertência, Röhr (2010: 217) explica que o ser humano é multidimensional e apresenta cinco dimensões consideradas básicas, indissociáveis e imprescindíveis, conforme quadro 1 apresentado a seguir:

\begin{tabular}{|c|c|c|c|c|}
\hline $\begin{array}{l}\text { Dimensão } \\
\text { Física }\end{array}$ & \begin{tabular}{|c|} 
Dimensão \\
sensorial
\end{tabular} & $\begin{array}{r}\text { Dimensão } \\
\text { emocional }\end{array}$ & $\begin{array}{l}\text { Dimensão } \\
\text { mental }\end{array}$ & Dimensão espiritual \\
\hline $\begin{array}{l}\text { Corporalidad } \\
\text { e físico- } \\
\text { biológica, da } \\
\text { qual em parte } \\
\text { nem temos } \\
\text { percepção } \\
\text { consciente. }\end{array}$ & \begin{tabular}{|l}
\multicolumn{1}{|c|}{ Representad } \\
a pelas \\
sensações \\
fisicas como \\
calor-frio, \\
dor-prazer, \\
etc. \\
Percepções \\
através dos \\
sentidos: \\
tato, visão, \\
audição, \\
olfato, \\
paladar.
\end{tabular} & $\begin{array}{l}\text { Abrange a } \\
\text { vida da } \\
\text { nossa } \\
\text { psique. Os } \\
\text { estados } \\
\text { emocionais } \\
\text { (medo, } \\
\text { insegurança, } \\
\text { euforia, etc.) }\end{array}$ & $\begin{array}{l}\text { Inclui, em } \\
\text { primeiro lugar, o } \\
\text { racional e lógico } \\
\text { no sentido mais } \\
\text { restrito; abrange } \\
\text { também a } \\
\text { capacidade de } \\
\text { reflexão, a } \\
\text { recordação, a } \\
\text { memória, a } \\
\text { imaginação e a } \\
\text { fantasia, a } \\
\text { compreensão e } \\
\text { criação de ideias } \\
\text { e finalmente a } \\
\text { nossa intuição - } \\
\text { em que sabemos } \\
\text { sem poder } \\
\text { justificar por que } \\
\text { sabemos. }\end{array}$ & $\begin{array}{l}\text { Não se confunde } \\
\text { dimensão espiritual } \\
\text { com religiosa. Nos } \\
\text { aproximamos da } \\
\text { dimensão espiritual, } \\
\text { por exemplo, } \\
\text { identificando } \\
\text { insuficiência das } \\
\text { outras dimensões em } \\
\text { relação ao ser humano } \\
\text { em suas } \\
\text { possibilidades. A } \\
\text { dimensão espiritual é } \\
\text { transcendente } \\
\text { enquanto as outras } \\
\text { dimensões são } \\
\text { imanentes. Das } \\
\text { dimensões imanentes } \\
\text { temos evidencias } \\
\text { constantes. A } \\
\text { dimensão espiritual } \\
\text { transcende a realidade } \\
\text { empiricamente } \\
\text { verificável e nem por } \\
\text { isso deixa de ser } \\
\text { realidade. Inclui-se } \\
\text { nesta dimensão os } \\
\text { valores éticos e } \\
\text { metafisicos, e com } \\
\text { isso, a ideia de Paz. }\end{array}$ \\
\hline
\end{tabular}


I - Quadro 1 - Elaborada pelas autoras com base em Röhr (2010: 219 e 220)

Estas dimensões são consideradas de ordem material, com densidades e qualidades distintas, e o autor estabelece uma escala delas, com graus de densidade material que percorrem da matéria mais densa, que é a matéria física, até a mais sutil que é a matéria espiritual. Elas se relacionam entre si de forma hierárquica e interdependente como vemos nos exemplos apresentados pelo autor:

[...] Muitas das relações entre as dimensões básicas se tornam mais compreensíveis partindo da realidade como escala entre a meteria física como a mais densa e a espiritual como a mais sutil. Podemos perceber que as realidades mais densas influenciam mais facilmente quase que instantaneamente as mais sutis. Quando algo causa uma dor forte, por exemplo, o nosso humor, quer dizer, o nosso lado emocional, muda instantaneamente. Estados emocionais desequilibrados, ao contrário, precisam às vezes de anos até se manifestarem como somatizações. Quer dizer, as realidades mais sutis não deixam de influenciar as mais densas. [...] O mais comum é constatar que desarmonias e bloqueios nas dimensões mais densas impedem facilmente as atividades e manifestações das esferas sutis. Uma alimentação deficitária, por exemplo, pode prejudicar capacidades de aprendizagem intelectual. $\mathrm{O}$ estado emocional de ira pode impedir a conexão com valores éticos relacionados à dimensão espiritual. (Röhr 2010: 222)

Dada a relação interdependente destas dimensões, não é possível interferir em uma delas sem considerar as outras, razão pela qual, se contemplamos alguma em detrimento de outras, como ocorre em nossa cultura que privilegia a dimensão mental, desprezando e desvalorizando as demais, temos a dissociação do ser humano o que prejudica a manifestação de suas potencialidades.

A ênfase em determinada ( $\mathrm{s}$ ) dimensão às custas da negligência de outra (s) produz dissociações, conforme os exemplos a seguir. Quando o sujeito exacerbando a racionalidade (dimensão mental) camufla necessidades corporais (dimensão material), exaurindo-se até a doença; ou quando as emoções (dimensão emocional) o impede de analisar uma situação racionalmente (dimensão mental), o que poderia o levar a atitudes impulsivas.

Quando isto ocorre temos a dissociação do sujeito, sendo que reiteradas dissociações vão obstruindo capacidades. A dimensão sensorial, que habilita à sensibilidade e à afetividade (capacidade de perceber o outro, perceber a natureza, capacidade estética) vai esmaecendo, e com isto há obstrução na dimensão espiritual que é responsável pela transcendência (capacidade de ir além, de ser mais; capacidade de conexão com o universo e assim também com o outro portanto capacidade de alteridade que é condição à ética). Estas dissociações formam um terreno fértil para que se instalem e se fortaleçam as condições que 
obstaculizam a paz, tais como a indiferença, o egoísmo, o individualismo, e com eles, o egocentrismo e a limitação cognitiva; como a limitação crítica e ética.

$\mathrm{O}$ egocentrismo se constitui fator determinante para a crise ética atual que relega o sujeito ao obscurantismo, situação onde o outro é tematizado e neutralizado; ou renegado à exclusão. $\mathrm{O}$ afeto predominante passa a ser a indiferença resultante do anestesiamento deste sujeito que se torna indiferente e limitado cognitivamente. Com isto temos a banalização da vida traduzida pelo distanciamento e objetificação do outro.

A dicotomia entre matéria e espírito, corpo e mente (Coelho 2011; Röhr 2010), se instaura na cultura ocidental que tem sido historicamente balizada por cisões; tais como a cisão corpo/alma (filosofia grega), corpo/espirito ou sagrado/profano (filosofia medieval), racionalidade/corporeidade/afetos/ emoções (filosofia moderna). Tais dicotomias produzem dissociações na forma de ver o mundo por parte do sujeito. Fato que se desdobra, consequentemente, no caráter sectário e hegemônico da cultura, quando é valorizado apenas um tipo de saber considerado racional-científico que desvaloriza saberes multiculturais e provoca o epistemicídio, como podemos interpretar a partir das ponderações de Boaventura de Sousa Santos (1997).

Estas dissociações resultam na dominação do homem em relação à natureza, exacerbando o antropocentrismo; do homem em relação à mulher, configurando o machismo - filho do patriarcalismo; do homem branco em relação ao negro, ao indígena, resultando no racismo; na dominação religiosa que extermina pessoas com a intolerância. Diante de um "eu dominante" e de "outros oprimidos", não há espaço para paz. Esta é a cultura considerada por Toro (2002) como um eco fator negativo o qual impede a expressão das potencialidades humanas, impedindo a paz individual e coletiva.

Considerando a definição para integração apresentada aqui, como uma condição à paz interior, esta fragmentação prejudica a integração do indivíduo e consequentemente da coletividade, pois como afirma Röhr (2010: 217)

A paz não depende só de acordos livres e justos entre as comunidades. Quando ela não habita as mentes de todos, continua sob ameaça constante. Se falarmos ainda em cultura de paz, expressamos que o espírito de paz precisa se tornar cultura, quer dizer, algo que penetra em todas as facetas da nossa vida, exterior e interior

Sendo assim, a vivência do entrelaçamento das dimensões apontadas por Ferdinand Röhr é o que possibilita a integração. E quando isto não ocorre, decorrente da super valorização de uma em detrimento de outras, ocorre a dissociação que enfraquece o ser humano, obstaculizando a seleção para o que conserva a vida: forma ampla de referirmo-nos a saúde física e psicológica e a vivência da transcendência (espiritualidade, ética). 


\section{Integração e dissociação}

A dissociação é a separação das partes pelo sujeito contemporâneo, que vê a realidade de forma estanque, dicotômica e binária sem que haja a reconexão que contemplaria a associação entre elas, o que habilitaria ao sujeito a percepção sistêmica da realidade.

É a visão sistêmica da realidade que possibilita ao sujeito a percepção da relação interdependente que há em de tudo o que existe, o que o levaria a assunção do compromisso e da responsabilidade decorrente da consciência sobre os efeitos de cada ação em um todo maior.

Quando não há integração, a percepção sistêmica se compromete, resultando na incapacidade de que se estabeleça a relação entre as partes de um sistema. Ou em outras palavras, incapacidade de que se estabeleçam relações entre um evento e outro. Como exemplos temos: o sujeito que, incapaz de ver a realidade sistemicamente, não percebe a relação entre desmatamento ou uso de agrotóxicos e saúde.

A incapacidade de perceber sistemicamente a realidade reduz a interpretação do sujeito a uma crônica visão dicotômica, resultando em déficit cognitivo. A inteligência é também condição para se ter e possibilitar paz. Este estado quando crônico caminha rumo às patologias, razão pela qual dizemos que temos uma sociedade adoecida (Weil 2003) instaurada sob a égide das necropolíticas (Mbembe 2018): termo que o filósofo Mbembe (2018) utiliza para a situação em que o extermínio do outro é legitimado politicamente enquanto um exercício de soberania.

As dissociações ocorridas inicialmente em nível corporal podem se agravar, refletindo dissociações psíquicas que são igualmente refletidas no juízo moral, balizando atitudes no que diz respeito à ética. Tal agravamento produz um crescimento vertiginoso de doenças psicossomáticas e psicológicas. De acordo com Toro (2002) as dissociações podem se manifestar nos níveis: motor (consiste em ver o próprio corpo não como uma unidade integrada, mas em partes isoladas), sensitivo-motor, afetivo e ídeo-motor (indicam uma dissociação psíquica que se reflete na conduta motora). Na prática estas dissociações se manifestam quando pensamento, sentimento e atitude (ação) ocorrem de forma incoerente.

À guisa de exemplificações, uma dissociação motora (quando o corpo é visto como partes isoladas) impede o sujeito de correlacionar uma enxaqueca recorrente com a exaustão que tem infligido ao seu organismo, visando responder à pressão obsessiva por rendimento; ou de relacionar a dor da enxaqueca com uma alimentação tóxica. Já uma dissociação sensitivo-motora pode ser exemplificada na incapacidade de locomover o corpo em prol de algo que traria benefícios ao sujeito, em função de um bloqueio emocional - afetivo. 
A atual cultura do empreendedor de si mesmo é herdeira do sentimento de culpa, tão útil à submissão do indivíduo, e terreno fértil à incoerência entre sentimentos e atitudes que ocorrem em função do temor da punição, face as transgressões dos valores culturais. Neste fértil terreno às incoerências a mente, mente a si mesma, com aparente desdém; mas o estado psicológico e espiritual produz a insônia e a ansiedade. A recorrência destas incoerências nas atitudes toma proporções que alcançam diversas áreas da atuação humana, ao que Toro (2002) denomina por dissociações existenciais. São as dissociações existenciais que demarcam uma cultura que pode se condicionar à desigualdade, ao preconceito, à opressão.

O desacordo consigo mesmo é proveniente de uma sociedade e educação que ignora a multidimensionalidade humana e as potencialidades genéticas, pois o sujeito não encontra condições no meio para agir coerentemente com o que seu "ser inteiro" demanda. A indiferença à necessária integração humana, que tem como consequência a dissociação, é proveniente de um axioma ocidental que valoriza a dimensão mental em detrimento das demais. Esta dissociação tomou proporções culturais refletidas nas diversas áreas da vida.

Ora, a cultura atual, extremamente materialista e tecnicista, valoriza resultados dos procedimentos técnicos sem se preocupar com aspectos éticos (como a saúde do sujeito ou as consequências de suas ações), condiciona a cada dia mais os sujeitos à produção a qualquer custo. A ação proceduristica assume que a dimensão mental sobreviveria sem as demais. Desta forma adoece gravemente a dimensão material por excesso de atividade; polui a dimensão sensorial, fere fortemente a dimensão emocional e ocasiona o enfraquecimento da dimensão espiritual.

O sujeito ferido e doente se adapta a esta realidade que o fere e o adoece de forma mecânica e alienada, perdendo a capacidade de reunir condições de transformá-la, produzindo esta cultura tóxica que vemos se fortalecer mundialmente - uma cultura cujo sentido axiológico favorece a indiferença e a belicosidade. Exemplos infelizmente não faltam: quando ser ético toma a conotação de ser ingênuo ou antiquado. $O$ sujeito precisar privar-se da manifestação de seu ser integrado. O constante estado de desacordo consigo mesmo que se constitui como a razão principal das dissociações, e que caracteriza o sujeito contemporâneo, se constitui produto-produtor de uma cultura que não favorece a paz.

A paz é, nestas condições prejudicada, quando as milhares de pessoas que sobrevivem sem as condições básicas de dignidade são ignoradas pela indiferença. Quando se fortalecem sistemas necropolíticos - hegemônicos e opressores - com modelos econômicos exploradores movidos pelo egoísmo, pela ganância e pela fragilidade cognitiva que resulta na ausência de ética. Quando o egocentrismo cega o próprio sujeito oprimido que, armadilhado pelo sistema econômico opressor, se esforça para ser empreendedor de si mesmo 
(Han, 2019); anestesiado pela ilusão de autonomia. Quando o oprimido oprime com seu preconceito. Ou quando aqueles e aquelas que gozam das necessidades materiais armadilham-se no isolamento, exaurindo-se na artificialização das relações; tornando-se reféns da banalização da vida identificada no tremendo aumento da depressão e do suicídio da atualidade.

Tal cenário poderia apagar qualquer luz que permita enxergar algum horizonte, não fossem perspectivas que insurgem outras possibilidades movendo forças biofílicas.

Os pressupostos dos referenciais epistêmico filosóficos aqui escolhidos, representam tal possibilidade. De acordo com Rolando Toro Araneda (2002) há no ser humano um potencial genético que, encontrando condições de expressarse, habilita o sujeito a autopreservação, capacitando-o à seletividade que recusa o que ameaça sua conservação, conforme propõe, também, o filósofo Espinoza (2018). Estas duas condições só são possíveis a partir da integração entre as dimensões humanas. (Röhr 2010).

Como já esclarecido, a paz coletiva depende da paz individual considerando principalmente duas situações: 1) a necessidade de suprir necessidades materiais básicas, não para sobrevivência visto que sobreviver meramente não resulta em paz; mas para gozar de dignidade (possibilidade de se ter paz). Tal condição significa na prática ter seus direitos de alimentar-se, acessar o que lhe produz saúde física e psicológica, gozar de bem estar físico, intelectual e estético garantidos e, 2) integrar suas cinco dimensões básicas para expressar seus potenciais, o que confere paz para além das necessidades materiais básicas, constituindo-se condição para esta.

É preciso alimentar o corpo, a alma e o espírito para experimentar sensações de paz, ainda que estas sempre se intercalem com sensações de ausência dela, dada a falta primária eterna no sujeito.

\section{A força biofílica que seleciona o que favorece a vida e a paz}

Para o filósofo Espinosa (2018), há no ser humano uma vontade de manter ou aumentar a força capaz de perseverar a existência. O ser humano é, em si esta força. A este impulso de sobrevivência ele denomina: "o esforço pelo qual cada coisa se esforça para preservar em seu ser". Que nada mais é do que "a essência atual da própria coisa” (Espinosa 2018: 251). Ou, o conatus. Para defender sua ideia de que o indivíduo humano tende a desejar o que favorece a conservação, o filósofo explica que no ser humano existe também, apesar de sua inscrição cultural que o caracteriza, uma instância natural de neutralidade moral que o ameaça constantemente, colocando-o em risco, sempre que age como que hipnotizado, desconsiderando valores que favoreçam a sua conservação. 
Este impulso de sobrevivência faz com que o sujeito deseje o que favoreça sua conservação, recuando e até lutando contra o que a ameaça. Inferimos aqui que esta força seletiva torna possível e é possibilitada pela expressão da potencialidade humana. Por isto vamos analisar esta possibilidade a partir da exposição do que seja e de como se expressa o potencial humano denominado por Toro (2002) como potencial genético, demarcando fatores que impedem sua expressão.

\section{Potencialidade Humana}

Rolando Toro Araneda, de forma análoga à Espinosa, propõe que há no ser humano um potencial genético que, embora seja inato, só se manifesta se encontrar condições para expressar-se nas interações do sujeito com o meio desde sua tenra idade, em um permanente e complexo entrelaçamento entre fatores endógenos e exógenos

É este potencial que impulsiona o sujeito à vida, no sentido animalinstintivo, e que também oferece as condições para a humanização, na medida em que o inscreve na cultura; porém, se ativo, induz o sujeito à distinção do que, neste meio cultural, o favorece ou o debilita, habilitando-o a selecionar o que o favorece. Daí a associação, aqui realizada, entre a expressão deste potencial humano proposto por Toro como propiciada e proporcionadora do conatus proposto por Espinosa. Tomando aqui, caminho diferente daquele do filósofo.

A expressão do potencial genético é, pois, a expressão das potencialidades da vida humana e são os seguintes os cinco canais por onde este potencial pode ou não se expressar, a depender das condições para que isto ocorra:

a vitalidade - que é a capacidade de conectar-se com a saúde, a vontade de viver, o ânimo;

a sexualidade - representada na libido, na energia vital, na capacidade de sentir prazer;

a criatividade que é a capacidade de recriação existencial (resolver problemas, criar alternativas e soluções, reinventar a própria existência). Também expressada nas diferentes manifestações estéticas;

a afetividade - capacidade de empatia e alteridade;

a transcendência - capacidade de passar de um estágio evolutivo a outro e de conexão profunda com o cosmo.

Estes cinco canais, quando encontram condições para se expressarem, favorecem por sua vez a expressão do potencial humano porque: possibilita 
a renovação orgânica indispensável à homeostase que, condicionando a saúde, oferece condição para o sujeito existir de forma saudável; possibilita a reintegração afetiva, indispensável à saúde mental e à vivência coletiva saudável; e permite o fortalecimento de uma vivência saudável. De forma sintética, estas potencialidades se constituem forças originárias e propiciadoras de vida, como explicou Toro (2002).

Como o meio se constitui eco fator negativo, estas forças se debilitam podendo esvanecer. É necessário ativar sempre os canais que possibilitam sua expressão para a manutenção de uma vida saudável.

Como? Quando a pessoa encontra potência produtora de capacidades, tais como as apresentadas a seguir resumidamente:

1) Capacidade de conectar-se com a saúde, priorizando por exemplo uma alimentação saudável. Capacidade de descansar quando seu organismo solicita, sem se exaurir em função das exigências desproporcionais do meio, conciliando vigília e repouso de forma harmônica; ação esta, fundamental à renovação orgânica que propicia o indispensável ciclo circadiano com o qual refazemos nossas forças produzindo energia vital. Tais capacidades correspondem, principalmente, ao canal de expressão da vitalidade

2) Capacidade de sentir prazer nas ações cotidianas como por exemplo, sentir e desfrutar cenestesicamente da água do banho fluindo na pele, do gosto de uma fruta, do carinho do contato e da carícia; condições estas fundamentais para que se goze do prazer genuíno nas relações afetivas e sexuais. Presença da energia libidinal ou, da libido, que é uma energia sexual a qual ultrapassa a relação sexual entre pessoas e com a qual mobiliza-se a energia vital como um todo, sendo fundamental à tomada de iniciativa. Tais capacidades são representadas pelo canal de expressão da sexualidade;

3) Capacidade de encontrar alternativas criativas para superação de obstáculos inerente à vida. Capacidade criadora tanto em relação à recriação existencial, transformações, como em relação a criação artística do ponto de vista estético. Representada pela Criatividade;

4) Capacidade de conexão profunda do outro de forma assimétrica. Hospitalidade à diferença. Capacidade de relacionar-se à base da alteridade. Afetividade para com quem não se tem laços, também; Capacidade de se colocar no lugar do outro. Empatia. Vinculada à linha da afetividade.

5) Capacidade de transcender no sentido de ir além, avançando em termos de evolução existencial. Capacidade de transtases. Capacidade de conexão com um todo maior: a natureza; o divino. Capacidade de espiritualidade que não se confunde à religiosidade. Representada na linha da transcendência

A expressão destes potenciais permite a reconstrução da estrutura orgânica sempre deteriorada no dia a dia das interações cotidianas que ocorrem em ambientes tóxicos. 
Integrados, estes cinco canais de expressão sintetizam o potencial humano que é genético, mas que precisa das condições para se manifestar.

A integração entre as dimensões básicas apresentadas por Röhr são imprescindíveis para que estes cinco canais possam expressar o potencial genético, o que dialeticamente produz tal integração, resultando na integração da identidade.

O que nos permite inferir que possibilitaria a ação do conatus proposto por Espinoza, posto que tal integração fortalece o sujeito, fortalecendo sua capacidade de seletividade (que pode ocorrer inconscientemente), e discernimento (mecanismo este consciente e ligado aos valores éticos). Da mesma forma nos permite inferir que tal integração pode proporcionar a sensação de paz, considerando a dimensão da individualidade, tendo em vista o que foi exposto em relação às cinco linhas de expressão do potencial genético.

As capacidades acima apresentadas produzem a sensação de estar em paz em função do sentido que o sujeito atribui à vida, que é decorrente da possibilidade de vive-la instintivamente com intensidade. A vida passa a ser valorizada. Em sentido hierofânico, tem-se a sacralidade da vida.

Desta possibilidade insurge um sujeito que está "de bem com a vida", popularmente falando. Trata-se de alguém para quem a vida tem valor porque a sente e a vive imanentemente com tal profundidade transcendente. Quando este sentimento se instala, pode ocorrer a ética da alteridade; quando o sujeito é capaz da hospitalidade que acolhe o outro que é diferente dele, pois o sentimento de sacralidade da vida é extensivo ao sujeito. Pode-se dizer que quem encontra a sensação de paz, não obstaculiza a paz alheia.

Mas como visto, são necessárias condições para a integração das dimensões humanas, que por sua vez habilitam os canais que expressam o potencial humano e fortalecem o conatus, ou a capacidade seletiva. E como também demonstrado, a cultura atual, pelas razões aqui apresentadas, não se constitui eco fator positivo, e sim eco fator negativo para que sejam ativados os canais que expressam o potencial humano, tornando o sujeito fraco.

Uma cultura que instiga a indiferença e a competividade, através da predominância de uma dimensão (a dimensão mental) que é - aparentementeútil para o sistema econômico vigente, por exemplo, negligenciando as outras dimensões, se constitui eco fator negativo para a expressão do potencial humano, enfraquecendo a força capaz de transformar a realidade opressora a partir da seleção do que produz vida, saúde e paz. E isto se constitui obstáculo à paz, conforme apresentaremos a seguir. 


\section{Adialética da a-sujeição como obstáculo à paz: a desigualdade econômica como obstáculo à expressão do potencial humano e a inexpressão deste potencial como facilitador desta desigualdade}

A falta do gozo das necessidades básicas, que representa falta do gozo da dignidade é, pois, um fator que impede a paz, individual e coletiva. A desigualdade econômica atinge os sujeitos sociais diretamente na violação do direito fundamental às condições materiais de uma vida digna, indo muito além, produzindo um niilismo atrofiante da esperança como referia-se Paulo Freire.

A desigualdade social tem proponentes com nome e endereço. Mas como adverte Fraser (2020: 35), não é possível compreender a ascensão e o poder destes que tem interesse que a desigualdade persista, sem iluminar as condições que a possibilitaram e mapear o processo pelo qual elas se desemaranharam. $\mathrm{O}$ que significa identificar a visão de mundo cujos valores permitem a opressão, a exploração e os totalitarismos.

Para isso a autora recorre ao conceito gramsciano de hegemonia como fio que esclarece tais condições. Como nos explica Fraser, o bloco hegemônico incorpora e dita regras axiológicas definidoras daquilo que é justo e correto e do que não é.

Desde pelo menos a metade do século XX, nos Estados Unidos e na Europa, a hegemonia capitalista foi forjada pela combinação de dois aspectos diferentes de direito e de justiça - um focado na distribuição, o outro no reconhecimento. $\mathrm{O}$ aspecto distributivo transmite uma visão sobre como a sociedade deve alocar bens divisíveis, especialmente os rendimentos. Esse aspecto diz respeito à estrutura econômica da sociedade e, ainda que indiretamente, às suas divisões de classe. $\mathrm{O}$ aspecto do reconhecimento expressa um senso de como a sociedade deve repartir o respeito e a estima, as marcas morais de pertencimento enquanto membros da sociedade. (Fraser 2020: 36).

É necessário identificar com precisão o que torna este processo desumanizante possível, fator este que permite a instalação desta falsa política progressista de reconhecimento, que mascara a mais perversa das opressões: a que Byung- Chul Han (2017) vai explicitar como a fabricação do sujeito como empreendedor de si mesmo ou, nas palavras do autor, "o sujeito que é livre, na medida em que não está submisso a outras pessoas que lhe dão ordens e o exploram; mas realmente livre ele não é, pois ele explora a si mesmo e quiçá por decisão pessoal" (Han 2017: 21).

Para Han, é a condição de sujeito voltado narcisicamente ao desempenho o que viabiliza esta cegueira com a qual o sujeito entorpece sua capacidade de percepção em relação a quanto está, na verdade, condicionadamente aprisionado quando pensa estar sendo livre: "esta lógica de reconhecimento - próprio - enreda o sujeito narcisista do desempenho de forma profunda em 
seu ego. (Han 2017: 11). Este último exemplo traduz, todavia, o sujeito que é vítima da desigualdade, sem, contudo, tratar do sujeito algoz, o que produz a opressão. Entretanto, são necessárias condições para existência e perpetuação da exploração e opressão.

Han analisa este fenômeno como um enfraquecimento ocorrido nos sujeitos devido à erosão do outro, que é possibilitada em decorrência do narcisismo do si mesmo que nega a alteridade, produzindo o evento lamentável por ele descrito como a agonia do eros (eros entendido enquanto condições à alteridade que ocorreria justamente quando a libido é investida ao outro e não prioritariamente na própria subjetividade. Eros como energia libidinal fortalecedora do sujeito, quando há o encantamento pelo outro e pela vida. Na presença de eros há amor. A morte de eros é a morte do amor e com ela a morte de sentido).

Ora, levar o eros a um estado agonizante é extremamente útil ao capitalismo hegemônico visto que, desprovido de sentido e de suas forças, o sujeito reduz sua capacidade de percepção crítica, conduzindo-se a um estado de alienação e de desencantamento cuja exacerbação traduz-se na a-sujeição do indivíduo. Condição que gera seu enfraquecimento, fortalecendo o egocentrismo, que invariavelmente leva o sujeito a ser tomado pelas ilusões de poder, favorecendo finalmente a sociedade do desempenho que é, por sua vez,

dominada pelo verbo modal poder em substituição e contraposição a sociedade da disciplina, tendo em vista que a partir de um determinado ponto da produtividade, o dever se choca rapidamente com seus limites; em face disto, o poder é enaltecido, à revelia de seu caráter ilusório, para a elevação da produtividade"[...] o apelo à motivação, à iniciativa e ao projeto é muito mais eficaz para a exploração do que o chicote ou as ordens. (Han 2017: 21).

O que vai colocar o indivíduo na posição de refém neste condicionamento - daí a a-sujeição - é a necessidade da liberdade. Porém a liberdade neste caso é ilusória, visto que, no fundo, quando o sujeito se torna explorador de si mesmo de forma auto licenciada, ele torna-se vítima e algoz ao mesmo tempo, conferindo a este fenômeno seu caráter de extrema perversidade, face a cega alienação que o caracteriza.

Tal fato demonstra que é possível haver exploração mesmo sem dominação, como adverte Han (2017: 22); assim como já advertira muito antes o filósofo Hegel com sua dialética "do Senhor e do Escravo" (Hegel 2005). Tomemos a metáfora hegeliana tratando a morte como possibilidade de insurgência mediante a transgressão do estabelecido hegemonicamente.

Este sistema econômico é por isso excludente e opressor. Está emaranhado na cultura e obstaculiza propositalmente a expressão dos potenciais humanos, dissociando o indivíduo e o enfraquecendo a ponto de se esvanecer a identidade, dando lugar a um egocentrismo refém que o torna empreendedor de si mesmo. 
Ocupado automaticamente em lucrar, ou em produzir (para sobreviver), este indivíduo ignora sua multidimensionalidade, alijando os canais de expressão da potencialidade humana e exaurindo a força seletiva, levando o eros, do ponto de vista da coletividade, a agonizar.

Torna-se evidente que um sistema econômico que produz desigualdades é um impeditivo à paz. Mas o que gera, possibilita e perpetua determinado sistema econômico, que não parece estar em consonância com a dignidade humana e com as condições que permitem a vida? Para as seguintes perguntas: quem mantem este sistema, porque o mantem, a partir de que mecanismo o faz, e para que o mantém, já temos respostas. Um sistema desigual perverso (econômico em sua base, mas infiltrado em todos os âmbitos forjando uma cultura belicosa), é mantido por quem tem e deseja ter sempre mais poder; é proveniente da ganancia de um egocentrismo cego; se mantém às custas da exploração e reificação das pessoas vulneráveis para que se perpetue a concentração do poder.

Mas resta sempre e continuamente a pergunta sobre quais as condições que possibilitam tamanha debilidade que permite o indivíduo escolher, ou permitir que seja mantida, uma cultura que alimenta um sistema necropoliticoeconômico que o maltrata, desfavorece a sua vida e a vida como um todo, ameaçando a sua permanência no planeta?

E este é o cerne de nossa reflexão. Muitos são os fatores que permitem a manipulação e a opressão que alienam o sujeito, produzindo uma cultura hegemônica, opressora e belicosa. Um fator é, sem dúvida, a dissociação do sujeito que favorece a manipulação, a opressão e a indiferença quando, obstaculizando a ação da força seletiva, o conatus, face a obstrução do potencial humano - o sujeito torna-se como cego, incapaz de compreender esta situação criticamente ou de encontrar estratégias para sua superação.

Enfraquecido torna-se refém: 1) vulnerável à condição de oprimido; ou 2) inerte/indiferente; ou 3) egocêntrico na condição de opressor.

Sim, o opressor é também refém do sistema (ousamos afirmar que ainda o é mais do que o oprimido) visto que, do ponto de vista da capacidade crítica, é extremamente vulnerável, dado o fato de que a opressão deliberada representa déficit cognitivo representado fundamentalmente pela obstrução ética (Coelho y Rebauças 2017). Trata-se de uma dissociação reveladora de comprometimentos de diversas naturezas: cognitivo, moral, ético e psicológico que em última instancia compromete o caráter, quando não encontra escrúpulos enquanto parâmetros para as atitudes. Espinosa nos diria que tal vulnerabilidade decorre de uma falha no impulso de preservação da vida. Toro explicaria que esta falha resulta do bloqueio da ativação dos canais de expressão do potencial humano. Aliás, é exatamente esta a finalidade da dissociação humana: o enfraquecimento para a mudança que se faz necessária à contra hegemonia, para que estas formas de exploração sejam perpetuadas. 
O desafio a estes arranjos colocado em prática pelas classes dominantes consiste na construção de um novo e mais persuasivo senso comum, ou em outras palavras, uma contra hegemonia juntamente com uma nova e mais poderosa aliança político traduzida em um bloco contra hegemônico (Fraser 2020: 36).

É, portanto, necessário que o sujeito insurja conectando-se com a força que seleciona o que favorece a vida digna, a vida como um todo. É necessário que o sujeito expresse seu potencial de humanização e seja capaz de combater todas as formas com as quais é possível que se estabeleçam e se fortaleçam as necropolíticas, provenientes e alimentadoras desta economia hegemônica e opressora que se infiltra na cultura.

Eis o que precisa ser combatido:

- o poder e a cegueira daqueles que manipulam o sistema econômico para manter a hegemonia visando o poder;

- a ingenuidade e ignorância daqueles que são vitimizados por este sistema de modo que, sem conseguir compreender seu mecanismo, tornam-se cúmplices enquanto empreendedor de si mesmos e seguem fieis e alienadamente as regras do sistema, o apoiando. Fato perceptível face aos rumos políticos do Brasil, principalmente nos últimos quatro anos, por exemplo;

- $\quad$ a exploração e opressão que excluem milhares de pessoas em função da desigualdade e do preconceito;

- e finalmente, combater a indiferença que tem anestesiado pessoas, enclausurando-as em seus egocentrismos com os quais isolam o outro ou o objetificam, artificializam as relações, fortalecem a banalização da vida, conduzindo a isolamentos que as trancafiam em suas cavernas, como nos advertia Platão há muito tempo atrás.

Quando a vida é banal, a injustiça, o desprezo, a opressão e até mesmo a morte não importam.

É a integração entre as dimensões básicas que, proporcionando a expressão do potencial e ação da força seletiva, pode levar o sujeito à reflexão crítica e à sensibilização que os habilitem a criar estratégias contra hegemônicas e recuperar o eros em nosso ethos. São os sentimentos, valores e saberes contra hegemônicos que representam hoje, no atual cenário mundial, possibilidades de se erguer uma cultura de paz.

Trata-se, pois, da necessidade de mudança de mentalidade e postura do sujeito a refletir mudanças em termos de valores culturais.

As recorrentes situações de opressão, violação da dignidade humana e destruição ambiental retratam valores que tem guiado as atitudes dos indivíduos. 
Ao valorizar a competitividade, instigamos a exploração; ao valorizar a vaidade egóica, instigamos a competitividade. A indiferença permite a descartabilidade da vida. A falta de sentido produzida pelo imediatismo, impede a consciência crítica e a sensibilidade, e assim, a consciência ética. E é neste sentido que podemos observar que a paz individual está associada à paz coletiva. Tais valores associam-se aos processos cognitivos porque o conhecimento e os saberes carregam uma carga axiológica. Estes valores são aprendidos e ensinados, o que demonstra que a saída está em ensinar e aprender outros valores.

O desafio é que se desenvolvam sujeitos conectados com a força conservadora da vida. Este sujeito precisa, para assim se desenvolver, encontrar espaços integradores, onde haja condições para a expressão dos seus potenciais de humanização que produza consciências cujos valores sejam contra hegemônicos.

\section{Educação para a Cultura de Paz}

O desenvolvimento do sujeito capaz de mobilizar estratégias contra hegemônicas só pode ocorrer por meio de processos educativos específicos que o possibilitem. Não se trata, portanto, de qualquer modelo educativo. Precisamos parar de gerar opressores. Precisamos parar de educar para a competitividade. Precisamos parar de estimular a vaidade em detrimento de um caráter forte: um caráter cujo conatus esteja presente.

Propor a possibilidade de mudança a partir da educação não significa um ideal abstrato. Trata-se de uma utopia realizável, pois esta possibilidade já é realidade para alguns em alguns lugares. Não está na esfera de um não lugar. Trata-se de um Sonho Possível, parafraseando Paulo Freire.

É possível identificarmos hoje, em pleno cenário mundial em que a hegemonia se constitui o pior e mais fatal vírus, modelos de sustentabilidade em âmbitos educativos e da vivência social coletiva. Sem nos determos a explicalos, citaremos alguns exemplos: a Agroecologia, a Permacultura, as Práticas Integrativas e Complementares de Saúde (PICS), a Antroposofia, a Ayurveda, a Ecopedagogia, a Justiça Restaurativa, o Direito Achado na Rua, a Comunicação Não Violenta (CNV), a Educação Biocêntrica, a Educação Popular, a Educação Waldorf, o Ecumenismo, a Educação em Direitos Humanos.

Considerando somente os exemplos apontados acima observam-se alternativas nas áreas: da saúde, da agricultura, da economia, da autonomia dos povos (outra lógica à substituir a ideia egóica de soberania), da alimentação, da engenharia e arquitetura, do direito, das religiões e, entrelaçando todas elas, temos a Educação como lugar de possibilidades delas. 
O que todas estas práticas em suas especificidades carregam em comum? O seu sentido axiológico, epistemológico e teleológico. Trata-se de uma mudança de postura frente a vida, reflete mudança de valores, que é possível devido a construção de saberes e conhecimentos. Os conhecimentos e saberes que embasam estas propostas refletem valores tais como: equidade, comunhão, solidariedade, partilha, coletividade, compromisso, responsabilidade, respeito, alteridade, entre outros. Valores que refletem uma cultura de paz. Se estabelecem a partir de uma lógica sistêmica, quando por exemplo, um sintoma de doença apresentado pelo organismo humano, é percebido em relação às circunstancias do sujeito, considerando seus fatores, tanto em decorrência das outras dimensões humanas, como fatores externos presentes na alimentação, que por sua vez se relaciona com a política e economia. Todos os aspectos da realidade estão interconectados.

Estamos diante de uma proposta sistêmica e Biocêntrica que considera a relação interdependente entre tudo o que existe, e que coloca a vida como centralidade ética e ecológica a partir da assunção do compromisso com práticas sustentáveis.

Precisamos repensar as bases da educação. Uma cultura de paz exige uma educação cujos valores propiciem, em seus processos, essa cultura.

\section{Considerações finais}

Paz não é um estado que individualmente pode ser conjugado com constância, visto ser o sujeito, marcado pela falta. Há possibilidade de que haja a sensação de paz, mas sempre intercalada com a ausência dela.

A paz individual está relacionada à paz coletiva. Embora alguém possa encontrar-se em um estado de paz em meio a um contexto belicoso, não é possível pensar a paz coletiva se os sujeitos da coletividade estiverem privados individualmente dela.

Há, portanto, uma relação interdependente entre individualidade e coletividade a partir da qual se produz cultura. O que remete a necessidade de se pensar a constituição e construção do sujeito, para pensar uma cultura de paz. Assim como há uma relação igualmente interdependente destes fatores com a educação e seus processos educativos, posto que são neles e a partir dela que os sujeitos se constroem e se constituem.

Atualmente estas conjugações encontram-se falhas, pois a cultura tem privilegiado valores hegemônicos com os quais alimenta-se um sistema econômico excludente, que tem interferido nas relações subjetivas em que a opressão, a exploração, a exclusão e a indiferença têm predomínio em relação às condições favoráveis à paz. 
O indivíduo é sujeito, porque reúne condições para tal mediante a expressão de seus potenciais humanizadores. Há no sujeito uma força seletiva que o faz escolher o que favorece sua vida e rejeitar o que a prejudica - o conatus. Mas esta força precisa ser ativada, o que está associado à manifestação de suas potencialidades, possíveis mediante a integração da multidimensionalidade humana. Quando o sujeito não encontra espaço propicio, face aos eco-fatores negativos à esta manifestação, há a alienação do sujeito, tornando-o indivíduo vulnerável à opressão, fraco para insurgir e transformar a realidade. A satisfação das necessidades básicas como alimentar-se, gozar de saúde e de bem estar são condições de possibilidade para a integração e expressão dos canais do potencial genético de uma pessoa. A situação de desigualdade material, na qual se encontra um contingente enorme de pessoas, configura um eco fator negativo que obstaculiza a expressão do potencial humano enfraquecendo o conatus. Dado enfraquecimento dificulta a mudança desta situação, desenhando uma macabra dialética que nos coloca em um dilema cuja solução é quase indecifrável: o indivíduo enfraquecido não encontra condições de afrontar aquilo que o debilita.

Apesar de tratar-se de um desafio de alta complexidade, a saída está na educação. Porque um sistema desigual e opressor precisa de personagens; autores protagonistas ou coadjuvantes para existir. São valores presentes na competitividade, no imediatismo, na arrogância, na vaidade, na ganância, na acriticidade, entre outros, que possibilitam a realidade opressora e desigual.

É preciso educar para outros valores, saberes e fazeres. Educar para a afetividade e solidariedade, e não para a indiferença. Educar para a cooperação e comunhão, e não para a competitividade. Educar para a democracia e não para a opressão. Educar para a esperança e para mobilizar a justa ira frente a todas as possibilidades de aniquilamento dela, como propôs Paulo Freire. Tais propostas educativas consideram a multidimensionalidade humana. Elas constroem espaços educativos, onde os canais que expressam as potencialidades humanas encontram espaços para manifestarem-se e são estimulados a partir de metodologias especificas para esta finalidade. Cabe relembrar que tais propostas já existem e é imprescindível privilegiá-las. Precisamos de uma educação que habilite os sujeitos à mudança necessária para que a atual cultura se transforme em uma cultura de paz.

Dada perspectiva não é ingênua, pois como ensinou Paulo Freire, a realidade não é um dado determinado. Enquanto sujeito histórico, estamos no mundo e podemos transformá-lo, o que se constitui finalidade educativa como possibilidade de o sujeito ser mais. Se esta é uma utopia, recorremos à Eduardo Galeano, citando Fernando Birri, quando disse que a utopia serve para caminharmos. 


\section{Referências Bibliográficas}

Adorno, T.: Educação e emancipação, Rio de Janeiro, Paz e Terra, 1995.

Capra, F: O Ponto de Mutação, São Paulo, Cultrix, 1982.

Cabezudo, A.: "Educación para la paz, los derechos humanos y el desarme: desafio pedagógico de nuestro tempo". en: PELIZZOLI, M. (ed.): Cultura de Paz restauração e direitos, Recife, Editora UFPE, 2010, pp.241-258.

Coelho, C.: A Ética Biocêntrica como encarnação da Alteridade: da vivência das transformações existenciais à mudança paradigmática, Tese de Doutorado, Salvador, UFBA, 2011.

Coelho, Carla y REBOUÇAS, G.: "Alteridade como premissa para a Justiça: uma questão cognitiva?”, en: Correia, A. y otros (ed): Heidegger, Jonas, Levinas. São Paulo, ANPOF, p. 19-39, 2017, pp. 19-39

Eliade, M.: Tratado de Historia de las Religiones, Ed. Cristiandad Madrid, 2000

Fraser, N.: O velho está morrendo e o novo não pode nascer, São Paulo, Autonomia Literária, 2020.

Freud, S.: O Mal-Estar na Civilização. Obras psicológicas completas de Sigmund Freud, edição standard brasileira/S.F.; com comentários e notas de James Strachey; em colaboração com Anna Freud; assistido por Alix Strachey e Alan Tyson; traduzido do alemão e do inglês sob direção geral de Jayme Salomão, Rio De janeiro, 1996, Vol XXI.

Freire, P.: Pedagogia da Autonomia: saberes necessários à prática educativa, São Paulo, Paz e Terra, 1996, Coleção Leituras, II Edição.

Freire, P.: "Utopia e democracia: os inéditos-viáveis na Educação Cidadã", en Azevedo, José Clovis. y otros: (ed): Utopia e democracia na Educação Cidadã, Porto Alegre: Editora da Universidade, UFRGS, 2000.

Freire, Ana Maria.: Notas, em Freire, P. (ed): Pedagogia da Esperança: Um reencontro com a Pedagogia do oprimido, Rio de Janeiro, Paz e Terra, 1992.

Freitas, Ana Lúcia.: Pedagogia da conscientização: um legado de Paulo Freire à formação de professores, Porto Alegre, EDIPUCRS, 2001.

Han, Byung-Chul.: Agonia do eros, Petrópolis, RJ, Vozes, 2017.

Hegel, G. W. F.: Lineamenti di Filosofia del Diritto. Tradução de Vincenzo Cícero, Milano, Rusconi Libri, 1996.

Hegel, G. W. F.: Fenomenologia do Espírito, Tradução de Paulo Meneses, 3 ed. Petrópolis, Vozes, 2005.

Hillman, J.: O código do ser: uma busca do caráter e da vocação pessoal, Rio de Janeiro, Objetiva, 2001

Levinas, E.: Totalidade e Infinito, Lisboa, EDIÇÕES 70, 1980. 
Meira, Ronny.: Meio Ambiente, Cinema e Espiritualidade: uma reconfiguração cognitiva para sustentabilidade socioambiental, Dissertação de Mestrado, Aracaju, UNIT, 2019.

Mbembe, A.: Necropolítica, 3. ed. ,São Paulo, n-1 edições, 2018.

Mbembe, A.: "NECROPOLÍTICA: biopoder soberania estado de exceção política da morte", Arte e Ensaios. Revista do ppgav/eba/UFRJ, 32 (dezembro, 2016) Disponível em https://revistas.ufrj.br/index.php/ae/ article/view/8993/7169. Acesso em maio de 2020.

Michaelis: Dicionário Brasileiro da Língua Portuguesa. Disponível em http:// michaelis.uol.com.br/busca? $\mathrm{r}=0 \& \mathrm{f}=0 \& \mathrm{t}=0 \&$ palavra $=$ biofilia. Acesso em maio de 2020.

Röhr, F.: "Cultura de paz: saúde mente e corpo pela contribuição da terapia floral”, en: Pelizzoli, M. (ed.): Cultura de Paz: restauração e direitos, Recife, Editora UFPE, 2010.

Santos, B.: Pela mão de Alice: o social e o político na pós-modernidade, São Paulo, Cortez, 4. ed, 1997

Spinosa, B.: Ética/Espinosa; tradução Grupo de Estudos Espinosanos, coordenação Marilena Chauí - 1 ed., 1 reimp. - São Paulo: Editora da Universidade de São Paulo, 2018, e 1677.

Streck, D. y Viola, S.: "A criança no Brasil: avanços e desafios na Década de cultura de paz e não violência”, en: Pellizoli, M. (ed.): Cultura de Paz: restauração e direitos, Recife, Editora UFPE, 2010.

Toro, R.: Biodanza: Integração existencial e desenvolvimento humano por meio da música, do movimento e da expressão dos potenciais genético, São Paulo, Olavobrás, 2002.

Weil, P. y otros: NORMOSE: a patologia da normalidade, Campinas, SP, Versus Editora, 2003.

Wilhelm, R.: I Ching: o livro das mutações, Tradução de Alayde Mutzenbecher y Gustavo Alberto Corrêa Pinto, São Paulo, Editora Pensamento, 1982 [1923]. 
